\section{Evaluation of Response to Pecan Scab Pathogen Race Using a Detached Leaflet Protocol}

\author{
Patrick J. Conner ${ }^{1}$ \\ University of Georgia, 4604 Research Way, Tifton, GA 31793
}

Additional index words. Carya illinoinensis, scab, vertical resistance, fungus, histology, screening

\begin{abstract}
A detached leaflet protocol was developed for the evaluation of resistance to Fusicladium effusum in a seedling pecan population segregating for resistance. Leaflets at half to full expansion were detached from seedling trees, sprayed with a conidial suspension (isolate De-Tif-3), placed in a polyethylene bag in a growth chamber, and evaluated microscopically 7 and 14 days after inoculation. The percentage germinated conidia producing subcuticular hyphae was the best determinant of susceptibility with genotypes producing more than $15 \%$ subcuticular hyphae considered susceptible. Leaflets at half expansion had higher percentages of subcuticular hyphae and gave a clearer separation between susceptible and resistant genotypes than leaflets at full expansion. An evaluation period of 14 days was preferable to 7 days to allow slower reacting genotypes to be better evaluated. The detached leaflet protocol was evaluated in contrasting environments and was found to be robust to differences in shading and leaflet wetness. Detached leaflet tests gave similar results to field inoculations but were superior in consistently detecting susceptible genotypes. This protocol will be useful in evaluating the inheritance of pecan leaf scab resistance in breeding progenies.
\end{abstract}

The pecan scab fungus $\{$ Fusicladium effusum (G. Winter) [syn. Cladosporium caryigenum (Ellis \& Langl.) Gottwald]\} is the most economically damaging pathogen of pecan [Carya illinoinensis (Wangenh.) K. Koch] in the humid growing conditions of the southeastern United States. Foliar and stem infections result in black circular lesions that under favorable conditions can result in severe leaf spotting, premature defoliation, and shoot death. Development of lesions on fruit shucks reduces yield and nut quality and if not controlled can result in crop failure (Hunter, 1983; Sparks, 1996). Commercial pecan plantings of susceptible cultivars can require up to 11 fungicide applications annually to control the disease (Ellis et al., 2000). F. effusum has developed resistance to benzimidazole group fungicides (Littrell and Bertrand, 1981) and reduced sensitivity to DMIs (Stevenson et al., 2004), and recent concerns over negative environmental health effects of pesticides has increased pressure to restrict their use (Guillebeau, 1998).

The development of scab-resistant cultivars with excellent agronomic characteristics and nut quality will greatly increase the profitability of pecan cultivation in the southeastern United States. Consequently, a major emphasis of pecan cultivar development for this region is the identification and incorporation of high levels of durable scab resistance into high-quality commercial cultivars (Goff

Received for publication 2 Nov. 2012. Accepted for publication 27 Nov. 2012.

${ }^{1}$ To whom reprint requests should be addressed; e-mail pconner@uga.edu. et al., 1998; Thompson and Conner, 2012). One of the most important factors to be considered in the development of a resistance screening protocol is the existence of multiple races $F$. effusum (Hunter et al., 1986). Differences in virulence among scab isolates were first reported by Demaree and Cole (1929) who used orchard inoculations to demonstrate that at least four races of the pathogen existed that differed in their ability to infect pecan cultivars. Converse (1960) used controlled inoculations to identify scab pathogen races and demonstrate that they were most virulent on their cultivar of origin. Conner and Stevenson (2004) investigated the virulence patterns of 12 monoconidial isolates on 19 pecan cultivars in field inoculations and found that most isolates were highly virulent only on their cultivar of origin and one or a few other cultivars. These results indicate that a large pool of differential and ephemeral resistance to scab resides in the pecan germplasm. To delineate these resistance genes, genetic tests with specific fungal isolates are needed.

Microscopic examinations of susceptible and resistant reactions in pecan leaves demonstrate that susceptibility is characterized by the vigorous growth of subcuticular hyphae in a radial pattern predominantly over the anticlinal cell walls (Conner, 2002; Diehl and Graves, 1994; Latham and Rushing, 1988; Yates et al., 1996). In contrast, resistant reactions are typified by the presence of a darkstaining halo directly below the appressorium and limited hyphal growth (Conner, 2002). Observation of resistant, susceptible, and intermediate reactions over time suggests that resistance may be mediated by the speed of plant cell wall modifications that limit the growth of the subcuticular hyphae (Conner and Stevenson, 2004).

Typical techniques for screening pecan germplasm for scab resistance involve field ratings for the presence of scab lesions on the leaves or nuts (Goff et al., 1998, 2003; Thompson and Grauke, 1994). However, rainfall in the spring of the year when leaves are young and susceptible is sometimes insufficient to develop severe disease on standard susceptible cultivars. Another disadvantage of this method is that variation in virulence in scab populations leads to different results among locations (Goff et al., 1998). Inoculation of field-grown trees with a suspension of spores has been successful (Conner and Stevenson, 2004) but requires a relatively large amount of inoculum and is very timeconsuming. More importantly, the results of field inoculations are often obscured by the presence of lesions from natural infections and variation in environmental conditions during each inoculation. Whole plant assays in controlled environments are difficult to use in pecan because of the large size of the tree.

To bypass these inherent difficulties in field tests for resistance, detached leaflet methods have been investigated for assessing cultivar resistance to pecan scab (Conner, 2002; Yates et al., 1996). Detached leaflet methods have the advantage of providing consistent, repeatable environmental conditions for the inoculation and incubation, facilitating reproducibility between tests. Additionally, rare isolates of the pathogen can be tested without being released into the field. The method was found to be successful in studying race-specific resistance reactions among pecan cultivars. However, it was not clear if it could be successfully used to predict the presence of the intermediate reactions, which are common among seedling progenies (Roberts et al., 1977; Thompson and Grauke, 1994). The objective of this study was to use a detached leaflet technique to detect interactions between seedling genotypes and pecan scab isolates. A comparison was made between fungal growth on detached leaves in a controlled environment and attached leaves in the field. In addition, experiment conditions were varied to determine the optimal testing environment and the robustness of the methodology.

\section{Materials and Methods}

Plant and fungal material. Pecan trees were grown at an experiment farm located in western Tift County (lat. $31^{\circ} 30^{\prime} 29.13^{\prime \prime} \mathrm{N}$, long. $83^{\circ} 39^{\prime} 4.49^{\prime \prime}$ W), GA. Seedling trees were selected from a population derived from the cross 'Elliott' $\times$ 'Desirable', which was made in 1999 by the author. Seedling trees were grown on their own roots and had never received fungicide sprays. Trees were fertilized with $560 \mathrm{~kg} \cdot \mathrm{ha}^{-1}$ of $10 \mathrm{~N}-4.4 \mathrm{P}-8.3 \mathrm{~K}$ in the spring of each year and received supplemental irrigation during the growing season. $F$. effusum isolate De-Tif-3 was grown from a single conidium originating from a scab 
lesion on a 'Desirable' leaf obtained from the same experiment farm in which the seedlings were grown. De-Tif-3 was cultured and stored using the methods described by Conner (2002). Conidial inoculum was prepared as described in Conner and Stevenson (2004). To ensure minimal changes of the pathogen during culture, the fungus was replated no more than three times before reverting back to a common frozen stock. All inoculations were made using a concentration of $1 \times 10^{6}$ conidia $/ \mathrm{mL}$.

Field inoculation. Field inoculations were made on 21 Apr. 2004 and again on 4 May 2004 by spraying expanding compound leaves with the conidial suspension until runoff using a handheld spray bottle. Each leaf consisted of several pairs of leaflets with a range of maturity. Fully expanded leaflets (which are resistant to infection) and very small immature leaflets were removed before inoculation. This left two to three pairs of leaflets ranging in maturity from $\approx 1 / 8$ to $3 / 4$ expansion. After inoculation, leaves were enclosed in a $10 \mathrm{~cm} \times 15 \mathrm{~cm} \times 4$-mil thick clear polyethylene resealable bag. A minimal amount of air was included in the bag to reduce the buildup of heat. After $48 \mathrm{~h}$, the leaves were removed from the bag and allowed to dry. Inoculated leaves were collected and rated for the presence of scab lesions 5 weeks after inoculation. Disease severity was assessed on individual leaflets on a scale of 1 to 4 , where 1 = no visible symptoms, 2 = pinpoint necrotic lesions with sparse or no sporulation, $3=$ chlorotic lesions with limited expansion and sporulation, and 4 = large, dark expanding lesions with abundant sporulation. Leaflets were scored as the most severe lesion observed on that leaflet. Seedlings were scored as susceptible if an inoculation produced a Type 4 lesion on any of the leaflets.

Detached leaflet Expt.1. Five seedling trees $(303,305,307,340$, and 352), which displayed diverse reactions to field inoculation, were chosen to evaluate the detached leaflet protocol. Leaflets were collected from seedling trees on 2 Aug. 2007. Leaflets were chosen that were either half-expanded or fully expanded but not yet mature as judged by suppleness and thickness. Detached leaflets were sprayed until runoff with a conidial suspension and placed in a clear polyethylene resealable bag as described in the previous section and suspended vertically in a growth chamber at $25{ }^{\circ} \mathrm{C}$ under a 16 -h photoperiod $\left(115 \mu\right.$ moles $\left.\cdot \mathrm{m}^{-2} \cdot \mathrm{s}^{-1}\right)$. Approximately $1 \mathrm{~cm}^{2}$ of tissue was sampled from the center of the distal lamina of each leaflet 7 and $14 \mathrm{~d}$ post-inoculation (PI) from six replicate leaflets. For each leaflet section, 25 germinated conidia with well-formed appressoria were examined microscopically on the abaxial side of the sample for the presence of halos and subcuticular hyphae using the methods of Conner and Stevenson (2004).

Detached leaflet Expt. 2. Three seedling trees $(303,305$, and 352) were used to evaluate the robustness of the detached leaflet test. Leaflets $1 / 2$ to $3 / 4$ expanded were collected on 18 Aug. 2007. Inoculation was done as outlined in Expt. 1. A wet treatment consisted of leaflets sprayed with excess water $2 \mathrm{~d}$ after inoculation ensuring abundant water in the polyethylene bag as determined by the presence of $\approx 1 \mathrm{~mL}$ of water in the bottom of the bag. A dry treatment was imposed using leaflets patted dry with a paper tissue $2 \mathrm{~d}$ after inoculation and daily thereafter. A shade treatment was imposed by placing leaflets in a static shielding bag (ULINE Corp., Atlanta, GA), which decreased measured light intensity by $\approx 45 \%\left(52 \mu\right.$ moles $\left.\cdot \mathrm{m}^{-2} \cdot \mathrm{s}^{-1}\right)$ after inoculation. A dark treatment was achieved by placing leaflets in polyethylene bags and then wrapping the bags in aluminum foil to exclude light. Finally, a cold treatment was imposed by placing inoculated leaflets in a growth chamber at $15^{\circ} \mathrm{C}$ with a 16 -h photoperiod. Leaflets were sampled and examined microscopically $7 \mathrm{~d}$ after inoculation as described previously.

Detached leaflet Expt. 3. Both parents and 56 random seedlings of the 'Elliott' $\times$ 'Desirable' cross were chosen for evaluation. Leaflets that were $\approx^{1 / 2}$ to $3 / 4$ expanded were inoculated as described for Expt. 1 and evaluated microscopically $14 \mathrm{~d}$ PI for the presence of halos and subcuticular hyphae. Twenty-five germinated conidia were examined on each replicate leaflet and three replicates were examined for each genotype as described previously.

Data analysis. Individual inoculated leaflets were considered a replicate for both Expts. 1 and 2 with a total of six replicates for each treatment. Percentage data were analyzed statistically after arsine-square root transformation before which a proportion of 0 had been replaced with $1 /(4 \mathrm{n})$ and a proportion of 1 had been replaced with $(n-1 / 4) / n$ to improve equality of variance in the angles. Inoculation study data were analyzed by analysis of variance with comparisons between genotypes examined with Tukey's test $(P<$ $0.05)$. Statistical analysis was performed using SigmaPlot 12.3 statistical software.

\section{Results and Discussion}

Field inoculation. The population 'Elliott' $\times$ 'Desirable' was chosen for study because one parent, 'Elliott', is widely recognized as one of the cultivars most resistant to pecan scab (Conner and Sparks, 2007), whereas 'Desirable' is a widely planted cultivar that has become very susceptible to scab (Wells and Conner, 2012). Previous research has shown that 'Desirable' is highly susceptible to the monoconidal isolate De-Tif-3, which was isolated from 'Desirable', whereas 'Elliott' was resistant (Conner, 2002; Conner and Stevenson, 2004). When seedlings from the cross 'Elliott' $\times$ 'Desirable' were inoculated in the field with De-Tif-3, they produced a range of symptoms ranging from no visible reaction to the typical susceptible reaction of large expanding lesions with abundant sporulation (data not shown). It was, however, difficult to interpret the results of the inoculations resulting from the variation displayed among the different inoculations on some seedling trees. This variation was likely the result of environmental differences between inoculations. Hot sunny weather placed heat stress on the leaves, which were enclosed in clear polyethylene bags to provide the moisture necessary for the infection process. We have noted that high temperatures in the summer can cause leaves to mature sooner and perhaps become developmentally resistant to infection. Also, it was impossible to visually determine if the lack of symptoms was the result of an escape from infection or a strong resistant reaction, which typically produces no macroscopic symptoms (Rushing and Latham, 1991).

Pecan leaves consist of several pairs of opposite leaflets attached to a central rachis, and the leaflets mature in progression from the basal to the apical leaflets. Pecan leaves are only susceptible to scab infection when they are immature (Turechek and Stevenson, 1998; Yates et al., 1996). In the field inoculations, the youngest leaves often escaped scab (Table 1). This was likely because the youngest leaves had not expanded much and thus had less surface area exposed to the inoculum. Immature leaves also have a higher density of glandular trichomes (Wetzstein and Sparks, 1983; Yates et al., 1996) and in microscopic examinations, I commonly observed that closely spaced trichomes in very young leaves prevented $F$. effusum conidia from reaching the leaf surface.

Detached leaflet Expt.1. Using the results of the field inoculations, five seedling trees were chosen, which displayed a range of symptoms to evaluate the detached leaflet protocol. Seedlings 303 and 307 gave consistent resistant reactions (Table 1). Inoculation of seedling 307 resulted in no visible symptoms, whereas seedling 303 developed pinpoint necrotic lesions similar to the 'Elliott' parent. Seedling 305 was susceptible with inoculation resulting in abundant lesions on several leaflets. Seedlings 340 and 352 produced intermediate disease reactions. Seedling 340 appeared to be susceptible because one inoculation produced lesions with abundant sporulation but the other inoculation only produced lesions with limited sporulation. Seedling 352 consistently produced lesions with only limited sporulation and restricted mycelial growth. Such a host reaction to inoculation is usually classified as an intermediate (Conner and Stevenson, 2004) or moderately resistant (Diehl and Graves, 1994) reaction.

To evaluate the effect of leaflet maturity on pathogen growth, two sets of leaflets were collected from each test seedling. The first set was half-expanded, representing the most susceptible stage of growth in field inoculations. The second set was fully expanded but still soft and supple, a stage that preliminary studies had indicated remained healthy for longer periods of time once detached from the tree. The use of these two stages allowed the comparison of the reaction of immature very susceptible leaflets to more mature leaflets that might survive longer once detached from the tree. 
Leaflets were examined microscopically to determine the percentage germinated conidia that produced halos, a typical resistant reaction (Conner, 2002), and subcuticular hyphae, a susceptible reaction (Latham and Rushing, 1988). Some germinated conidia produced neither a dark-staining halo nor subcuticular hyphae. Because it was not clear whether this lack of reaction signified resistance or escape from infection, they were not included in the analysis. Leaflet maturity did not have an effect on the percentage of germinated conidia, which produced halos at either 7 or $14 \mathrm{~d}$ PI (Tables 2 and 3). Leaflet maturity did have a strong influence on the percentage of germinated conidia that produced subcuticular hyphae at $7 \mathrm{~d}$ and $14 \mathrm{~d}$ PI (Tables 2 and 3). In general, the effect of using more mature leaves appears to be a simple reduction in the percentage of conidia forming subcuticular hyphae; however, there was a significant interaction between leaflet age and genotype. This confirms previous research, which shows that more mature leaflets inhibit the growth of fungal mycelia within the leaf leading to complete inhibition at full maturity (Turechek and Stevenson, 1998; Yates et al., 1996).

As expected, genotype influenced the percentage of conidia that produced a halo reaction or subcuticular hyphae. There was generally good agreement between pathogen growth on detached leaflets (Tables 2 and 3 ) and the visual estimate of disease severity after field inoculations (Table 1). Susceptible seedling 305 had the lowest percentage of halos and highest percentage of subcuticular hyphae at $7 \mathrm{~d}$ PI field inoculation (Table 2). Field-resistant seedling 307 had the highest percentage conidia producing halos but was not statistically different from seedlings 303 , 340 , and 352 for percentage of subcuticular hyphae. The reaction of the other three seedlings was intermediate for pathogen development at $7 \mathrm{~d}$ PI with a moderate percentage of conidia producing halos and moderate subcuticular hyphal progress. By 14 d PI, separation of these seedlings was more clear (Table 3). The percent of conidia producing halos and development of subcuticular hyphae was not different for the susceptible seedlings 340 and 305. Seedling 303 and 307 were not different from each other and displayed a resistant reaction with a high percentage of conidia producing a halo and little mycelial development. Seedling 352, which gave an intermediate reaction in the field inoculation, also presented an intermediate reaction in the detached leaflet test. However, susceptibility of seedling 352 , as judged by the formation of subcuticular hyphae, was not significantly different from seedlings 303 and 307, which are considered resistant (Table 3), suggesting that it should be classified as a resistant type.

Detached leaflet Expt. 2. The robustness of the detached leaflet protocol was tested by applying several contrasting environmental conditions. Seedlings 303, 305, and 352 were chosen representing a strongly resistant, a susceptible, and a moderately resistant reaction,

Table 1. Results of field inoculation of pecan genotypes with F. effusum isolate De-Tif-3.

\begin{tabular}{|c|c|c|c|c|c|c|c|c|}
\hline \multirow{3}{*}{$\frac{\text { Genotype }}{303}$} & \multicolumn{8}{|c|}{ Disease reaction ${ }^{2}$} \\
\hline & \multirow{2}{*}{$\begin{array}{c}\text { Replication } \\
\mathrm{a}\end{array}$} & \multicolumn{2}{|c|}{ Basal pair ${ }^{y}$} & \multicolumn{2}{|c|}{ Middle pair ${ }^{y}$} & \multicolumn{2}{|c|}{ Apical pair ${ }^{y}$} & \multirow{2}{*}{$\begin{array}{c}\text { Avg } \\
1.7\end{array}$} \\
\hline & & $2^{z}$ & 2 & 2 & 2 & 1 & 1 & \\
\hline 303 & $\mathrm{~b}$ & 2 & 2 & 2 & 2 & 2 & 1 & 1.8 \\
\hline 305 & $\mathrm{a}$ & 4 & 4 & 4 & 2 & 1 & 1 & 2.7 \\
\hline 305 & $\mathrm{~b}$ & 4 & 4 & 4 & 4 & 1 & 1 & 3.0 \\
\hline 307 & $\mathrm{a}$ & 1 & 1 & 1 & 1 & 1 & 1 & 1.0 \\
\hline 307 & $\mathrm{~b}$ & 1 & 1 & 1 & 1 & & & 1.0 \\
\hline 340 & $\mathrm{a}$ & 4 & 4 & 4 & 4 & 1 & 1 & 2.7 \\
\hline 340 & $\mathrm{~b}$ & 3 & 3 & 3 & 3 & 2 & & 2.8 \\
\hline 352 & $\mathrm{a}$ & 3 & 3 & 3 & 1 & 1 & 1 & 2.0 \\
\hline 352 & $\mathrm{~b}$ & 3 & 2 & 2 & 1 & 1 & 1 & 1.7 \\
\hline Desirable $^{\mathrm{x}}$ & $\mathrm{a}$ & 4 & 4 & 1 & 1 & 1 & 1 & 2.0 \\
\hline Desirable $^{\mathrm{x}}$ & $\mathrm{b}$ & 4 & 4 & 1 & 1 & 1 & 1 & 2.0 \\
\hline Elliott $^{\mathrm{w}}$ & $\mathrm{a}$ & 2 & 2 & 1 & 1 & 1 & 1 & 1.3 \\
\hline Elliott $^{\mathrm{w}}$ & $\mathrm{b}$ & 2 & 2 & 1 & 1 & 1 & 1 & 1.3 \\
\hline
\end{tabular}

${ }^{2}$ Disease reaction: $1=$ no visible symptoms, $2=$ pinpoint necrotic lesions with sparse or no sporulation, $3=$ chlorotic lesions with limited expansion and sporulation, $4=$ large, dark expanding lesions with abundant sporulation. Rating represents the most susceptible reaction visible on each leaflet. Leaflets were rated 5 weeks post-inoculation.

${ }^{y}$ Apical leaflet pairs were $\approx 1 / 8$ fully expanded and basal leaflet pairs were $\approx 1 / 2$ fully expanded at the time of inoculation.

${ }^{\mathrm{x}}$ Susceptible control.

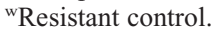

Table 2. Effect of genotype and leaflet age on fungal development at $7 \mathrm{~d}$ post-inoculation in detached pecan seedling leaflets inoculated with $F$. effusum isolate De-Tif-3. ${ }^{2}$

\begin{tabular}{|c|c|c|c|c|}
\hline \multirow[b]{3}{*}{ Genotype } & \multicolumn{2}{|c|}{ Percent halo reaction } & \multicolumn{2}{|c|}{ Percent subcuticular hyphae formation } \\
\hline & \multicolumn{2}{|c|}{ Leaflet maturity } & \multicolumn{2}{|c|}{ Leaflet maturity } \\
\hline & Half-expanded & Fully expanded & Half-expanded & Fully expanded \\
\hline$\overline{303}$ & $73 b^{y}$ & $67 \mathrm{~b}$ & $3.7 \mathrm{~b}$ & $1.7 \mathrm{~b}$ \\
\hline 305 & $25 \mathrm{c}$ & $38 \mathrm{c}$ & $64.8 \mathrm{a}$ & $30.3 \mathrm{a}$ \\
\hline 307 & $94 \mathrm{a}$ & $95 \mathrm{a}$ & $0.5 \mathrm{~b}$ & $0.0 \mathrm{~b}$ \\
\hline 340 & $59 \mathrm{~b}$ & $50 \mathrm{~b}$ & $16.1 \mathrm{~b}$ & $3.8 \mathrm{~b}$ \\
\hline 352 & $45 \mathrm{~b}$ & $72 \mathrm{~b}$ & $12.9 \mathrm{~b}$ & $3.7 \mathrm{~b}$ \\
\hline \multicolumn{5}{|c|}{ Main effects of leaflet maturity $(\mathrm{M})$ and genotype $(\mathrm{G})$} \\
\hline $\mathrm{M}$ & & \multicolumn{2}{|c|}{$P=0.002$} \\
\hline & \multirow{2}{*}{\multicolumn{2}{|c|}{$\begin{array}{c}P<0.001 \\
\text { NS }\end{array}$}} & \multirow{2}{*}{\multicolumn{2}{|c|}{$\begin{array}{l}P<0.001 \\
P=0.032\end{array}$}} \\
\hline$M \times G$ & & & & \\
\hline
\end{tabular}

${ }^{2}$ Leaflets were examined microscopically and the percentage of germinated conidia with a halo or percentage of conidia with subcuticular hyphal growth was determined.

${ }^{y}$ Mean total within each column with a common letter are not different based on analysis of variance with Tukey's test $(P=0.05)$.

$\mathrm{NS}=$ nonsignificant.

Table 3. Effect of genotype and leaflet age on fungal development at $14 \mathrm{~d}$ post-inoculation in detached pecan seedling leaflets inoculated with F. effusum isolate De-Tif- $3 .^{z}$

\begin{tabular}{|c|c|c|c|c|}
\hline \multirow[b]{3}{*}{ Genotype } & \multicolumn{2}{|c|}{ Percent halo reaction } & \multicolumn{2}{|c|}{ Percent subcuticular hyphae formation } \\
\hline & \multicolumn{2}{|c|}{ Leaflet maturity } & \multicolumn{2}{|c|}{ Leaflet maturity } \\
\hline & Half-expanded & Fully expanded & Half-expanded & Fully expanded \\
\hline$\overline{303}$ & $84 \mathrm{ab}^{\mathrm{y}}$ & $72 \mathrm{ab}$ & $0 \mathrm{~b}$ & 1 \\
\hline 305 & $28 \mathrm{c}$ & $49 \mathrm{c}$ & $54 \mathrm{a}$ & 21 \\
\hline 307 & $80 \mathrm{a}$ & $82 \mathrm{a}$ & $3 \mathrm{~b}$ & 0 \\
\hline 340 & $36 \mathrm{c}$ & $47 \mathrm{c}$ & $57 \mathrm{a}$ & 18 \\
\hline 352 & $52 \mathrm{bc}$ & $66 \mathrm{bc}$ & $13 \mathrm{~b}$ & 0 \\
\hline \multicolumn{5}{|c|}{ Main effects of leaflet maturity $(M)$ and genotype $(G)$} \\
\hline$\overline{\mathrm{M}}$ & \multirow{2}{*}{\multicolumn{2}{|c|}{$\begin{array}{c}\text { NS } \\
P<0.001\end{array}$}} & \multirow{2}{*}{\multicolumn{2}{|c|}{$P<0.001$}} \\
\hline G & & & & \\
\hline $\mathrm{M} \times \mathrm{G}$ & \multicolumn{2}{|c|}{ NS } & \multicolumn{2}{|c|}{$P=0.007$} \\
\hline
\end{tabular}

${ }^{2}$ Leaflets were examined microscopically and the percentage germinated conidia with a halo or the percentage conidia with subcuticular hyphal growth was determined.

${ }^{y}$ Mean total within each column with a common letter are not different based on analysis of variance with Tukey's test $(P=0.05)$.

$\mathrm{NS}=$ nonsignificant.

respectively, to evaluate the protocol. Leaflets were only examined at $7 \mathrm{~d}$ PI because by $14 \mathrm{~d}$ PI, most treatments resulted in severe leaflet mortality. The percentage of conidia producing halo reactions and subcuticular hyphae was significantly influenced by the environment, genotype, and there were significant interactions between genotype and 
environment (data not shown). In all experiments, the most noticeable effect was the result of low temperature. Leaves placed in the growth chamber set at $15{ }^{\circ} \mathrm{C}$ had reduced percentage of conidia producing halos and less development of subcuticular hyphae (Fig. 1) as compared with other treatments, which took place at $25{ }^{\circ} \mathrm{C}$. Noticeably fewer conidia germinated in this treatment suggesting that $15{ }^{\circ} \mathrm{C}$ is too low for vigorous pathogen growth and development (data not shown). Although other experiments have shown that infection can occur at temperatures as low as $10{ }^{\circ} \mathrm{C}$ (Gottwald, 1985), the temperature was only maintained for during the inoculation period and thereafter seedlings were grown in a greenhouse at a presumably warmer temperature.

The dark environment had approximately double the percentage of conidia with subcuticular hyphae as compared with the standard environment for all three genotypes tested (Fig. 1B). Interestingly, darkness only reduced the percentage of conidia producing halos in the susceptible seedling 305 (Fig. 1A). Although darkness appears to favor subcuticular growth, shading of leaves did not have an effect on the percent of conidia producing halos or on the percent of conidia with subcuticular hyphal growth. Thus, although light is necessary for the protocol, it does not appear to be particularly sensitive to the amount of light. The wet environment did not have a significant effect compared with the standard environment on either the percentage of conidia causing halos or the percentage of conidia with subcuticular hyphae. This is not surprising because the leaves in the original protocol are sprayed with conidia and remain quite moist in the polyethylene bags. The dry treatment did not have a significant effect on the resistant seedlings, but there were more conidia developing halos and fewer conidia developing subcuticular hyphae compared with the standard treatment on the susceptible seedling 305 .

Based on Expts. 1 and 2, a protocol was chosen to evaluate a larger number of seedlings. The standard protocol was chosen over the dark incubation protocol because the leaves remained healthier allowing them to be examined at $14 \mathrm{~d}$ PI, whereas the leaves maintained in the dark showed severe necrosis at $14 \mathrm{~d}$ PI. The dry protocol was not chosen because it narrowed the difference between the susceptible and resistant seedlings. The results of the wet and shade protocols were not significantly different from

A.

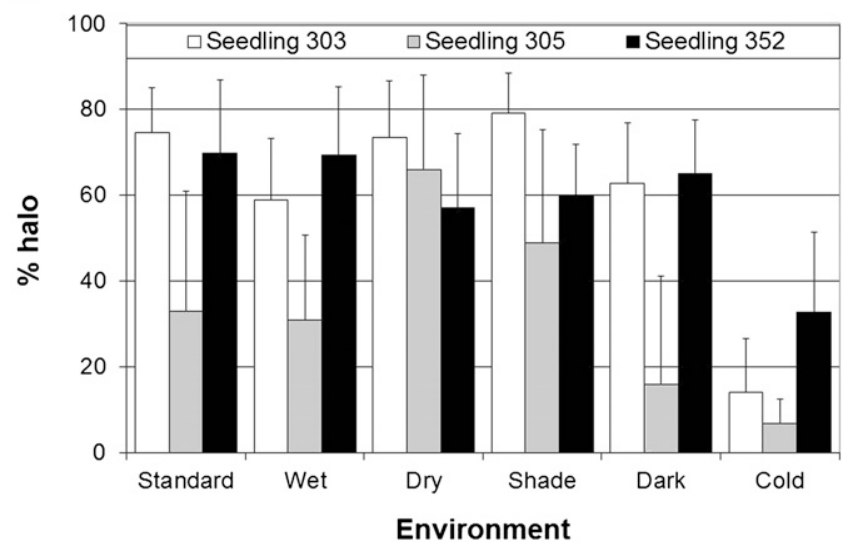

B.

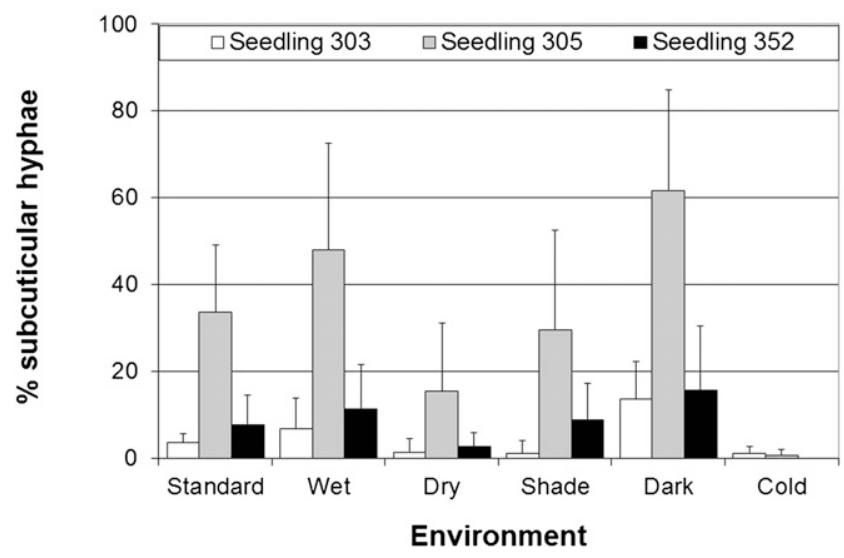

Fig. 1. Effect of environment on fungal development in detached pecan seedling leaflets inoculated with F. effusum isolate De-Tif-3. Leaflets were examined microscopically $7 \mathrm{~d}$ post-inoculation and the percentage germinated conidia with a halo (A) or subcuticular hyphal growth (B) determined. Twentyfive germinated conidia were examined for each leaflet and error bars represent the SE of six replicates. Seedling 303 was resistant, seedling 305 was susceptible, and seedling 352 was moderately resistant in the control inoculations. the standard protocol, so the standard protocol was chosen for further testing. A time period of $14 \mathrm{~d}$ PI was chosen to evaluate the inoculations so that slower-reacting, susceptible genotypes like seedling 340 could be separated from the moderately resistant genotypes like seedling 352 . It was necessary to determine which factor, halo formation or subcuticular hyphal growth, to use in classifying genotypes as resistant or susceptible. Although halo formation was lower in susceptible genotypes, it did not separate the moderately resistant 352 and susceptible 340 , whereas the formation of subcuticular hyphae differentiated the two seedlings. Leaves half-expanded were chosen over fully expanded leaves because there was no significant difference for the percentage of conidia with subcuticular hyphae on fully expanded leaves among seedlings (Table 3).

Detached leaflet Expt. 3. A selection of 56 seedlings to be tested was randomly chosen from the 'Elliott' $\times$ 'Desirable' population. A histogram of the percent conidia with subcuticular hyphae produced in detached leaflet tests in this population gives a bimodal distribution with a cutoff between the two subpopulations in the range of $15 \%$ to $25 \%$ conidia with subcuticular hyphae (Fig. 2). A cutoff of $15 \%$ conidia with subcuticular hyphae was chosen as the delineation between susceptible and resistant seedling genotypes because it is the midpoint between the $13 \%$ conidia with subcuticular hyphae produced on young (most susceptible) leaves of the resistant seedling 352 and the $18 \%$ conidia with subcuticular hyphae produced on fully expanded (most resistant) leaves of the susceptible seedling 340 at $14 \mathrm{~d}$ PI (Table 3). The $15 \%$ subcuticular hyphae cutoff gives a 23:33 (resistant:susceptible) ratio of seedlings, which is not significantly different from a $1: 1$ ratio $\left(\chi^{2}=1.78 ; P \approx 0.2\right)$. Altering the cutoff value would not affect these results because only five seedlings fall within the $10 \%$ to $25 \%$ range of conidia with subcuticular hyphae.

The principal purpose of developing this detached leaflet protocol was to enable the rapid screening of seedlings with specific isolates of $F$. effusum. The results of the detached leaflet protocol compared well with those of field inoculation (Table 4). Seven of the eight classification differences between the two protocols were the result of seedlings being classified resistant in the field inoculation and susceptible in the detached leaflet inoculation. These seedlings are most likely susceptible genotypes considering it was not uncommon for seedlings to have a maximum rating of 4 (susceptible) in one field inoculation replicate and a rating of 2 or 3 (resistant) in another replicate. This suggests that full expression of disease symptoms may depend on environmental factors that are difficult to control in the field inoculations. Although previous studies had shown the use of detached leaflet tests in identifying broad differences in susceptibility, this is the first study to evaluate a detached leaflet protocol on a segregating population. 


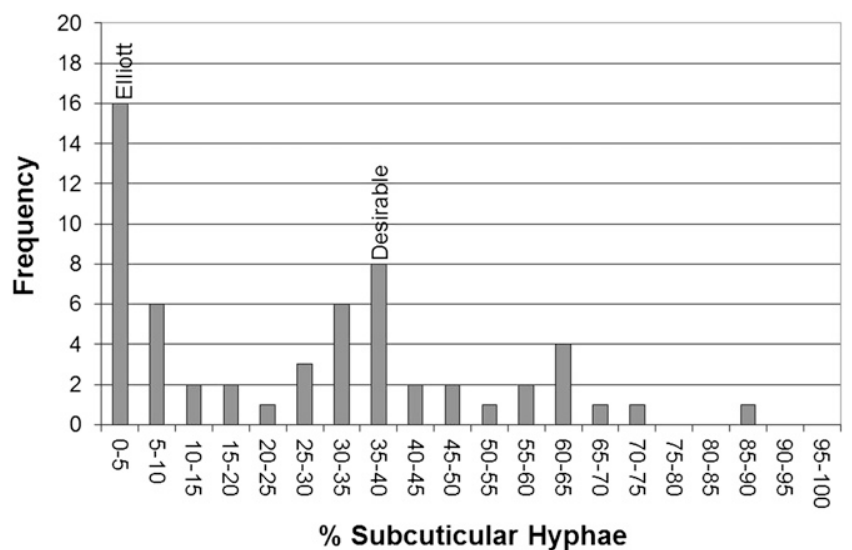

Fig. 2. Histogram of the percentage germinated conidia that produced subcuticular hyphae after inoculation of detached leaflets of 56 seedlings of the cross 'Elliott' $\times$ 'Desirable' with $F$. effusum isolate De-Tif-3. Leaflets were examined microscopically $14 \mathrm{~d}$ post-inoculation and the percentage germinated conidia with a susceptible (subcuticular hyphal growth) reaction determined. Twenty-five germinated conidia were examined for each of three replicate leaflets. The percentage subcuticular hyphae produced on the parental cultivars is indicated above the corresponding bars.

Table 4. Comparison of the detached leaflet protocol to the field inoculation protocol for screening pecan for resistance to the scab pathogen $F$. effusum (isolate De-Tif-3) in 56 seedlings of the cross 'Elliott' $X$ 'Desirable'.

\begin{tabular}{llccc}
\hline & & \multicolumn{2}{c}{ Field inoculation $^{z}$} & \\
\cline { 3 - 4 } & & Resistant & Susceptible & Total \\
\hline Detached leaflet inoculation $^{y}$ & Resistant & 22 & 1 & 23 \\
& Susceptible & 7 & 26 & 33 \\
& Total & 29 & 27 & \\
\hline
\end{tabular}

${ }^{z}$ Seedlings were considered susceptible if one or more inoculations produced Type 4 lesions. All seedlings were inoculated at least twice.

${ }^{y}$ Seedlings were considered susceptible if the percent germinated conidia producing subcuticular hyphae on three detached leaflets averaged $15 \%$ or above.

Using this protocol, seedlings could be reliably classified as resistant or susceptible. The detached leaflet protocol will allow breeding programs to screen progenies for resistance to particular isolates so that the genetic control of resistance to $F$. effusum can be better understood.

\section{Literature Cited}

Conner, P. and D. Sparks. 2007. 'Elliott' pecan. J. Amer. Pom. Soc. 61:55-60.

Conner, P.J. 2002. A detached leaf technique for studying race-specific resistance to Cladosporium caryigenum in pecan. J. Amer. Soc. Hort. Sci. 127:781-785.

Conner, P.J. and K.L. Stevenson. 2004. Pathogenic variation of Cladosporium caryigenum isolates
Goff, W.D., M.L. Nesbitt, and C.L. Browne. 2003. Incidence of scab and foliage condition on pecan cultivars grown without fungicide or insecticide sprays in a humid environment HortTechnology 13:381-384.

Gottwald, T.R. 1985. Influence of temperature, leaf wetness period, leaf age, and spore concentration on infection of pecan leaves by conidia of Cladosporium caryigenum. Phytopathology 75:190-194.

Guillebeau, P. 1998. What to do about the food quality protection act? Or how can we protect the pesticides we need? Proc. Southeastern Pecan Growers Assn. 91:65-69.

Hunter, D., T. Thompson, and R. Sanderlin. 1986. Control of pecan diseases through genetic resistance. Proc. Southeastern Pecan Growers Assn. 79:51-54.

Hunter, R. 1983. Influence of scab on late season nut drop of pecans. Plant Dis. 67:806-807.

Latham, A.J. and A.E. Rushing. 1988. Development of Cladosporium caryigenum in pecan leaves. Phytopathology 78:1104-1108.

Littrell, R. and P. Bertrand. 1981. Management of pecan fruit and foliar diseases with fungicides. Plant Dis. 65:769-774.

Roberts, D.D., R.E. Hunter, and D.C. Campbell. 1977. Breeding for resistance to pecan scab. Proc. Southeastern Pecan Growers Assn. 70:58-60.

Rushing, A. and A. Latham. 1991. Some ultrastructural observations of Cladosporium caryigenum growth in pecan leaves. Phytopathology 81 : 1102-1108.

Sparks, D. 1996. A climatic model for pecan production under humid conditions. J. Amer. Soc. Hort. Sci. 121:908-914

Stevenson, K., P. Bertrand, and T. Brennamin. 2004. Evidence for reduced sensitivity to propiconazole in the pecan scab fungus in Georiga. Phytopathology 94:S99 (Abstr.).

Thompson, T. and P. Conner. 2012. Pecan, p. 771802. In: Badenes, M. and D. Byrne (eds.). Fruit breeding. Springer, New York, NY.

Thompson, T.E. and L.J. Grauke. 1994. Genetic resistance to scab disease in pecan. HortScience 29:1078-1084

can. HortScience 39.553-557.

Converse, R.H. 1960. Physiologic specialization of Fusicladium effusum and its evaluation in vitro. Phytopathology 50:527-531.

Demaree, J.B. and J.R. Cole. 1929. Behavior of Cladosporium effusum (Wint.) Demaree on some varieties of pecan. J. Agr. Res. 18:363-370.

Diehl, S. and C. Graves. 1994. Characteristics of pecan scab lesions on mockernut hickory and pecan cultivars of differing susceptibility. Plant Dis. 78:512-516.

Ellis, H.C., P. Bertrand, and T.F. Crocker. 2000 2000 Georgia pecan pest management guide. Univ. of Ga. Coop. Exten. Serv. Bull. 841.

Goff, W.D., M. Nesbitt, R. Mullenax, F. Raspberry, and B. Graves. 1998. Pest-resistant cultivars as a way to reduce input costs. Pecan South. 31:6-9.
Turechek, W.W. and K.L. Stevenson. 1998. Effects of host resistance, temperature, leaf wetness, and leaf age on infection and lesion development of pecan scab. Phytopathology 88:12941301.

Wells, L. and P. Conner. 2012. Pecan varieties for Georgia orchards. Univ. of Georgia Cir. 898

Wetzstein, H.Y and D. Sparks. 1983. Anatomical indices of cultivar and age-related scab resistance and susceptibility in pecan leaves. J. Amer. Soc. Hort. Sci. 108:210-218.

Yates, I.E., D. Maxey, S. Lee, D. Sparks, and C.C. Reilly. 1996. Developing the pecan scab fungus on susceptible and resistant host and nonhos leaves. J. Amer. Soc. Hort. Sci. 121:350-357. 